\title{
Architectural Requirements for Improving Social Interactions in Subway Stations: An Evidence Based Design Approach
}

\author{
Hessam Ghamari ${ }^{1}$, Cherif Amor ${ }^{2}$ and Karim Mardomi ${ }^{3}$ \\ 1. Department of Design, Texas Tech University, Lubbock 79415, USA \\ 2. Department of Interior Design, Virginia Commonwealth University, Doha 3263, Qatar \\ 3. Department of Architecture and Urbanism, Iran University of Science and Technology, Tehran 1684613114, Iran
}

\begin{abstract}
Environmental design is concerned with the function of people within an environment and their interactions. Subway stations spaces are important examples of public spaces that are in close connection with the social life of people. Also, the fact that the social interactions and relations between people and city environments are becoming indispensable for subway station space indicates that these spaces play an essential role in urban life. This paper addresses the result of a study conducted by the authors on the influential elements pivotal to the improvement of social interactions in subway stations. The theory of John Lang in Urban design with consideration of social interaction was considered in this study. The objective of the study was to identify the architectural requirements in improving social interaction between people and environment in subway station spaces according to an evidence based design approach. To do so, relevant literature in different disciplines, architecture, urban design, social sustainability and so on, were reviewed. Next, the most important environmental factors which contribute to human behavior in public spaces were derived and analyzed. Data of the study were collected via questionnaires filled out by the users of Tehran's subway stations. The collected data were analyzed and the architectural elements/requirements for improving social interactions were classified. The results of the study indicate that in the case of architectural requirements, contribution to the improvement of social interactions, design considerations for physical and mental safety, accessibility and lighting are the most important factors.
\end{abstract}

Key words: Social interaction, subway station, architectural requirements, evidence-based design, human behavior.

\section{Introduction}

The development of human societies, their increasing requirements toward bettering life, and the limitation of existing resources highlight the transportation need in countries. In this regard, reaching a faster, safer, cheaper and more convenient transportation system has been one of the most important goals of human societies for many years [1]. Today, new technologies have led to safer, more energy-efficient and environment-friendlier rail transportations. Subway stations, as one of the most important type in rail transportations, are in close

Corresponding author: Hessam Ghamari, Ph.D. candidate, research/teaching assistant, research fields: architecture and interior design. E-mail: Hessam.ghamari@ttu.edu. relationship with the urban spaces and public life of people in cities. Stations create new user behaviors and requirements that cause them to be considered as one of the most critical issues in the field of architecture and urban planning [2]. Subway stations are settings where large numbers of unrelated people are forced to share the same space while waiting. As a result, even though subway stations are primarily designed as transportation nodes, they, by default, assume the secondary function as public spaces that a large number of city dwellers use.

There are two main approaches in relation to the principles of subway station design. First approach considers the subway station as a place which merely facilitates the transportation for the users. In this approach, the potential of space is limited to the 
functional purposes [3]. However, second approach, from a broader perspective, looks for creating a public space which improves the social interaction of the users [4]. According to this approach, evaluation of influential architectural factors which contribute to different aspects of human factors should be taken into consideration [5].

A station building, also known as a head house, is the main building of a passenger train station. Nasreazadani [6] indicated that the station is an environment which consists of a complex of official and residential buildings and the platforms that facilitates the transportation. Overall, according to the different definitions of subway stations, it can be described as an urban area which provides not only inner city transportation but also subway stations acts to connect the human beings to each other and improve their interaction with the urban environment. Lang [7] indicated that in public spaces, social behavior patterns and architectural space potentials are in close relationship to each other. Carmona et al. [8] believed that current stations are public urban places which should be considered as an area for improving the social interaction and social life of the citizens. According to Lang [7] and Carmona et al. [8], social interaction plays an important role in public spaces.

The close relationship between the subway network and social life promotes these stations' influence on the life of people socially, culturally and economically [9]. Furthermore, subway stations could organize the public spaces and improve the image of the city [10]. The study of environmental space qualities in subway stations is one of the crucial measures that contribute to increase the users' satisfaction. In this regard, the appropriate accessibility and safety should be taken into consideration [11]. Dusmiscevis and Sariyildiz [9] classified the characteristics of space qualities in subway stations in three different areas: functional, psychological and structural. Alavi and Ranjbar [12] indicated that architectural factors which contribute to human factors are categorized in physical, functional, and psychological sections. Dusmisevic and Sariyildiz [9] notified that design of subway stations should be in close relationship with the users' needs, abilities and limitations. Table 1 displays different ideas about the qualities of subway stations design consistent with human factors which have been classified in four different areas.

\section{Objectives}

Since subway stations play an important role of social life, their contribution to the human life should be investigated. Pace et al. [4], Dusmiscevis and Sariylidiz [9] and Salahshoor [3] highlighted the importance of the role of subway stations in improving social life in the city. Alavi and Ranjbar [12] studied some aspects of the role of entrances of Tehran subway stations from point of contribution to social life perspectives. According to this study, there are some problems in the social role of Tehran subway stations, some of which have been showed in Figs. 1-4. This study attempts to assess different subway stations in order to inform the architectural requirements which contribute to improvement of the social interactions in Tehran subway stations toward sustainability goals. In this regard, different architectural factors in specific subway stations in Tehran were considered. The information provided in this report could be

Table 1 Architectural factors in connection with human factors from different studies perspectives.

\begin{tabular}{ll}
\hline Category & Architectural factors \\
\hline Safety/security & Safety [11], supervision, attendance of users' safety and comfortable. \\
Physical/functional & $\begin{array}{l}\text { Accessibility, way finding, consideration of pedestrian movement [11], furniture, seating space, disabled people } \\
\text { accessibility [13], distinction between pedestrian and driver flows [14]. }\end{array}$ \\
Psychological/ & Social interaction [4], intimate and friendly space, sense of place, nostalgia (Afsharnaderi, 2010). \\
interpersonal & $\begin{array}{l}\text { Proportion and harmony of the space, material and color [3], human body dimension, space flexibility [10], } \\
\text { Aesthetic }\end{array}$ \\
\hline
\end{tabular}




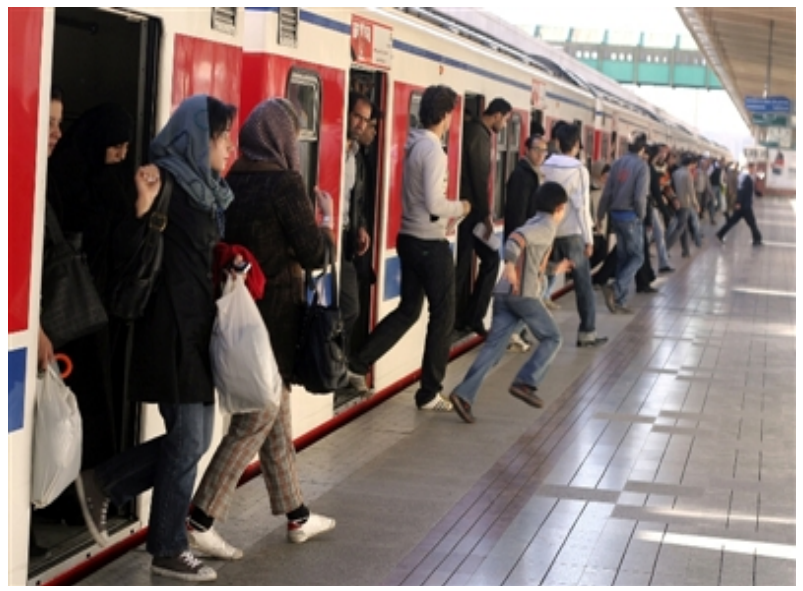

Fig. 1 Overcrowded space in Tehran subway station.

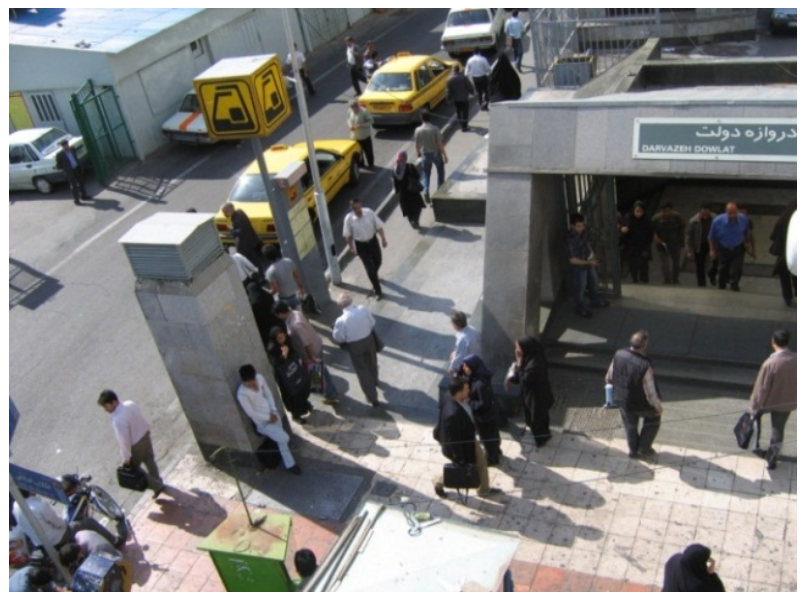

Fig. 2 Lack of design consideration in station's entrance.

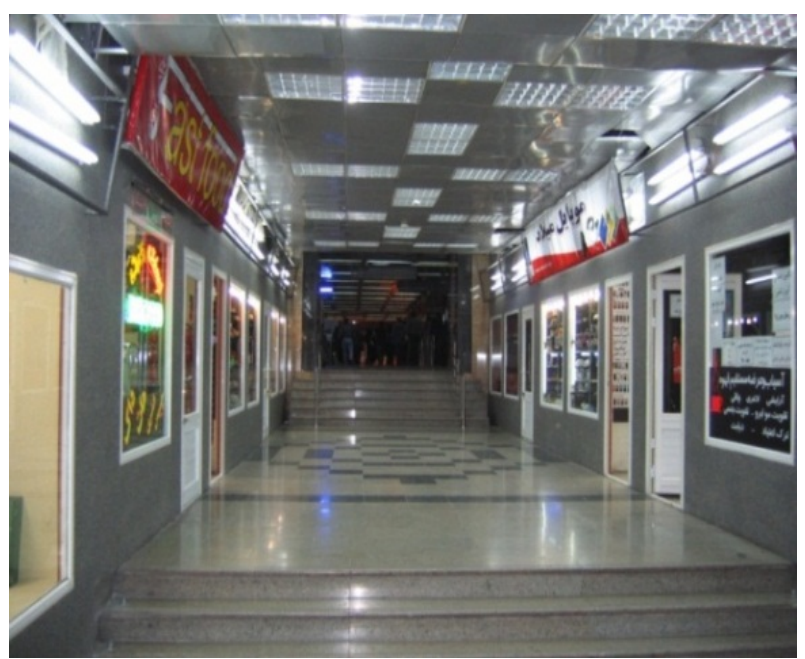

Fig. 3 Lack of consideration of disabled people.

implemented in existing and future subway stations to promote a stronger social interaction toward ergonomic goals.

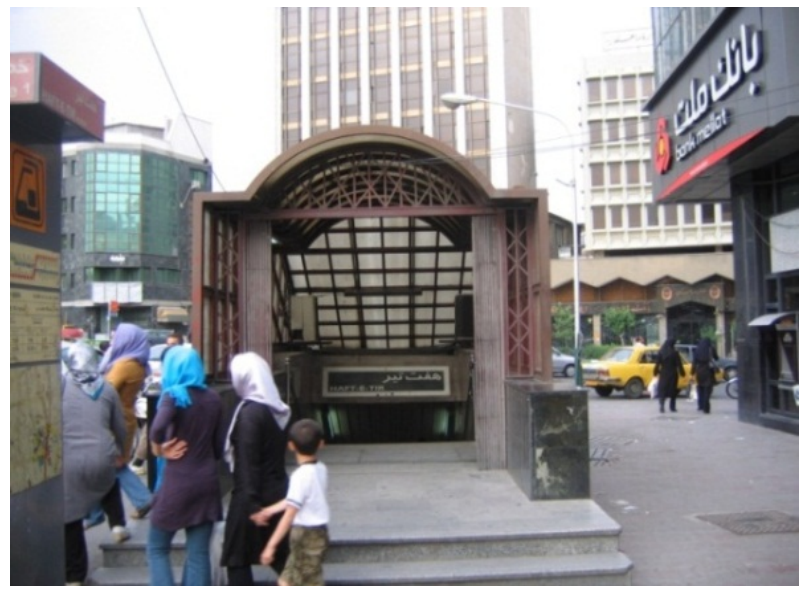

Fig. 4 Poor design of the station entrance.

\section{Methods}

Related literature reviewed journal articles and reports of studies in multiple disciplines - architecture, transportation, environmental design and environment psychology-were studied to identify the existing knowledge in subway station design from the human behavior perspective. Next, 146 users, according to sample size selecting [15], were asked to fill out a questionnaire to identify the major problems in Tehran subway stations. The questions in the questionnaire forms were seeking for finding the most important environmental factors which contribute to improving social interaction inside the subway stations. For instance, the users were asked to evaluate how much they agree or disagree with the association between lighting and social interactions. All questionnaire forms were filled out in different times (10 a.m. to 6 p.m.) on three different days (Monday, Wednesday and Friday) in the second week of June 2009. Six questionnaires were disregarded because the lack of reliability. The remaining 140 users consisted of 91 male and 49 female users with the mean age of 26.7 years old. Tehran subway network map was studied and analyzed to find the subway stations to be included in the study. The users were randomly selected in 1 st, 2nd, 4th and 5th lanes of Tehran subway stations to make sure that all above ground and under ground stations were included (Fig. 5). The stations were 


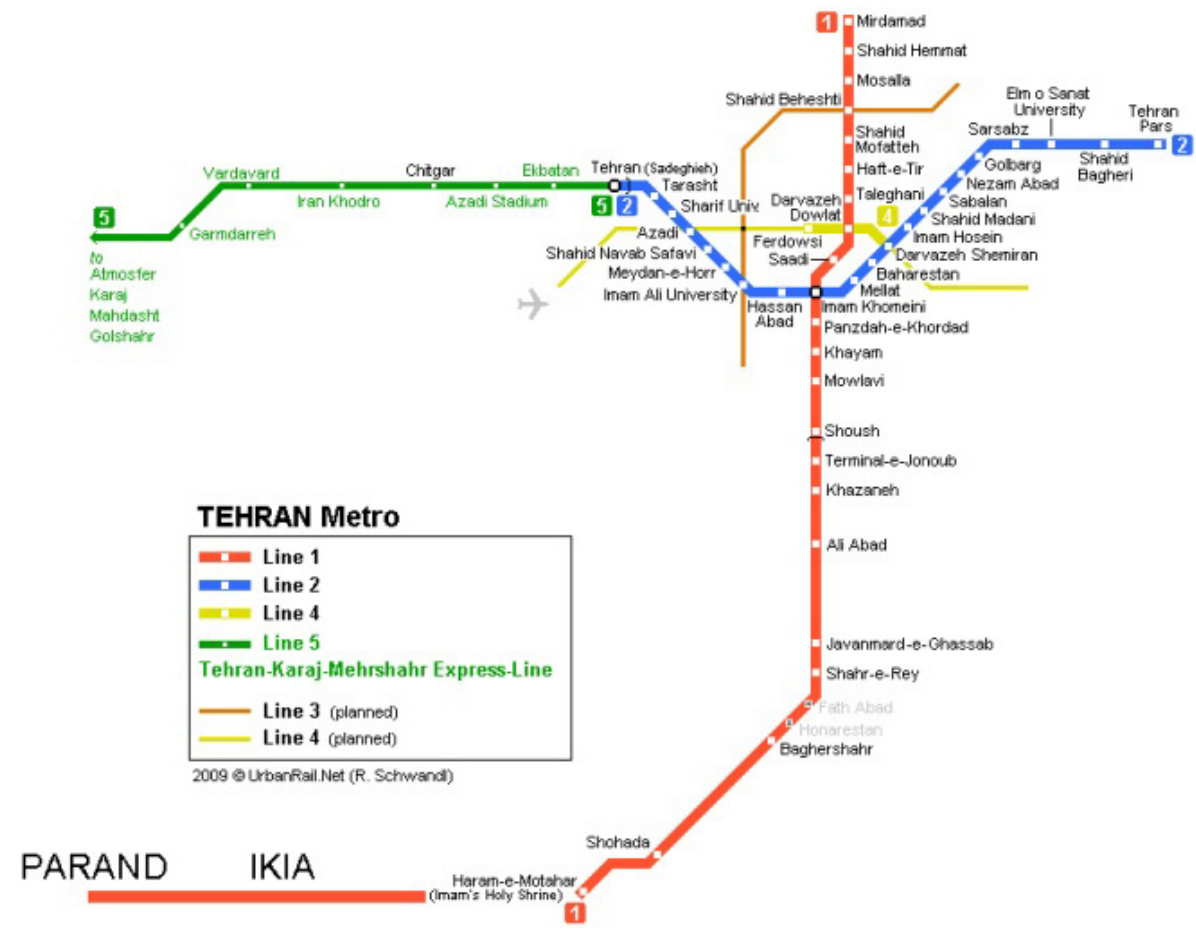

Fig. 5 The location and direction of different lanes of Tehran subway network.

observed by the authors and analyzed architecturally. Next, according to the data analysis and field studies in specific number of the stations, the problems and deficiencies of subway station design from the perspective of human factors were derived and concluded, and architectural requirements toward the improvement of social interaction in subway stations were indicated. The analyzed data were represented by graphic design and diagrams. In the final step, with the consideration of the results of the study, the proposed design solution of the subway station in Parand city was presented. According to the importance of the stations, the questionnaire forms were distributed between users. Sadeqieh station, because of its importance in connection to Karaj city and its greater size in comparison to other stations, had more users (18) to participate in the study. Additionally, Emam Khomeini station, as the central station and the main connection of first and second lanes had 15 users to participate in the study (Table 2).

The first, second, fourth and fifth lanes, as the main subway lines of public transportation in Tehran, were the settings of the study. Therefore, the stations in these two lines were the places that users were asked to fill out the questionnaires. Fig. 5 shows the location and direction of different lanes of subway network in Tehran [16].

Table 2 Classification of Tehran subway station according to the number of users participated in the study.

\begin{tabular}{lcllllll}
\hline Station & Numbers & Station & Numbers & Station & Numbers & Station & Numbers \\
\hline Shahid Madani & 2 & Sharif & 2 & Tehranpars & 8 & Azadi & 5 \\
Sadeqieh & 18 & Shahid Mofateh & 1 & Hasan Abad & 2 & Emam Hossein & 4 \\
Elmosanat & 2 & Tarasht & 3 & Haghani & 3 & Emam Ali & 1 \\
Fadak & 1 & Ali Abad & 1 & Darvazeh Shemiran & 1 & Baharestan & 3 \\
Qolhak & 14 & Farhangsara & 9 & Sarsabaz & 3 & Beheshti & 1 \\
Mosala & 1 & Golbarg & 2 & Mirdamad & 16 & Meidan Hor & 9 \\
& & Emam Khomeini & 15 & Hemmat & 1 & Haft Tir & 10 \\
\hline
\end{tabular}




\section{Findings}

\subsection{Problems in Tehran Subway Stations}

One of the sections of the survey conducted in selected subway stations intended to reveal the main problems in subway stations. Overall, $67 \%$ of the respondents indicated that there are problems in subways stations. Field studies of the specific subway stations in Tehran and the results of the survey revealed some problems and deficiencies in the station spaces as following:

- overcrowded spaces inside and outside the station;

- weakness of social interaction between people and environment;

- unfriendly and cold environment;

- poor connection with the city and other public spaces;

- concentration on (moving) hallways and corridors rather than spaces for gathering and interacting;

- not suitable consideration for pedestrian at the main entrances;

- function instead the quality of space.

Although the limitation of finances for transportation paired with the growing number of users cause some of these problems such as the overcrowded spaces and long periods of time between arriving trains, remained unsolved, design intervention aligned with the human behavior can solve some of these problems and create better public space.

\subsection{Architectural Factors and Human Factors in Subway Stations}

In this step, users of Tehran subway network were asked to indicate which architectural factors can influence on social interaction in subway stations. To do so, the answers were collected in the Likert-type scale. Table 3 displays the users' answers. The results of this table indicated that the majority of users believe that these factors are influential in human factors of subway stations. In average, $44.67 \%$ of the users answered "Completely agree" and only $1.6 \%$ answered "Completely disagree". Among these factors, accessibility and safety (60\%) have been described as the most influential factors.

$N=$ Completely agree $\times(+2)+$ Agree $\times(+1)+$ Neutral $\times(0)+$ Disagree $\times(-1)+$ Completely disagree $\times(-2)$.

Next, the architectural factors in Table 1 were scaled and compared to each other. The results of the scaled factors are displayed in Fig. 6. The data were analyzed in the way that the score for each architectural factor was determined by adding the numbers of Completely

Table 3 Architectural factors and human factors in subway stations-users' perspectives.

\begin{tabular}{|c|c|c|c|c|c|}
\hline Architectural factors & $\begin{array}{l}\text { Completely agree } \\
\text { (very positive) } \\
\% \text { (number) }\end{array}$ & $\begin{array}{l}\text { Agree (positive) } \\
\% \text { (number) }\end{array}$ & $\begin{array}{l}\text { Neutral } \\
\% \text { (number) }\end{array}$ & $\begin{array}{l}\text { Disagree (negative) } \\
\% \text { (number) }\end{array}$ & $\begin{array}{l}\text { Completely disagree } \\
\text { (very negative) } \\
\% \text { (number) }\end{array}$ \\
\hline Social interaction & $30(42)$ & $44(60)$ & $16(23)$ & $7.8(11)$ & $2.8(5)$ \\
\hline Space attractiveness & $50(70)$ & $32(46)$ & $7.8(11)$ & $7(10)$ & $2.8(4)$ \\
\hline Visual accessibility & $51(72)$ & $32(46)$ & $7(10)$ & $8(12)$ & $0(0)$ \\
\hline Transparency & $40(57)$ & $45(64)$ & $8.5(12)$ & $5(7)$ & $0(0)$ \\
\hline Accessibility & $60(84)$ & $32(46)$ & $2.8(4)$ & $4.2(6)$ & $0(0)$ \\
\hline Noise & $51(71)$ & $28(40)$ & $5(7)$ & $13(19)$ & $2.1(3)$ \\
\hline Lighting & $50(70)$ & $42(59)$ & $4.6(9)$ & $1.4(2)$ & $0(0)$ \\
\hline $\begin{array}{l}\text { Furniture (design and } \\
\text { layout) }\end{array}$ & $36(51)$ & 49 (69) & $10(14)$ & $3.5(5)$ & $0.7(1)$ \\
\hline Artworks & $40(57)$ & $33(47)$ & $20(28)$ & $5(7)$ & $0.7(1)$ \\
\hline Signs and symbols & $37(52)$ & $46(65)$ & $10(14)$ & $5.7(8)$ & $0.7(1)$ \\
\hline $\begin{array}{l}\text { Views and } \\
\text { perspectives }\end{array}$ & $30(43)$ & $30(42)$ & $25(35)$ & $12(18)$ & $1.4(2)$ \\
\hline $\begin{array}{l}\text { Safety (physical and } \\
\text { mental) }\end{array}$ & $60(85)$ & $28(40)$ & $5.7(8)$ & $2.8(4)$ & $2.1(3)$ \\
\hline
\end{tabular}


agree $\times(+2)$, Agree $\times(+1)$, Neutral $\times(0)$, Disagree $\times$ $(-1)$, Completely disagree $\times(-2)$. In addition, Fig. 6 shows the interrelationships between architectural factors which affect social interaction in subway stations. The results from Fig. 6 indicated that safety (physical and mental), accessibility, and lighting are the most important factors which can contribute to improvement of social interaction in public subway stations.

These architectural factors are categorized in four different areas: security/safety, aesthetic, functional/physical, and psychological/interpersonal. The interrelationships between these factors were displayed in Fig. 7.

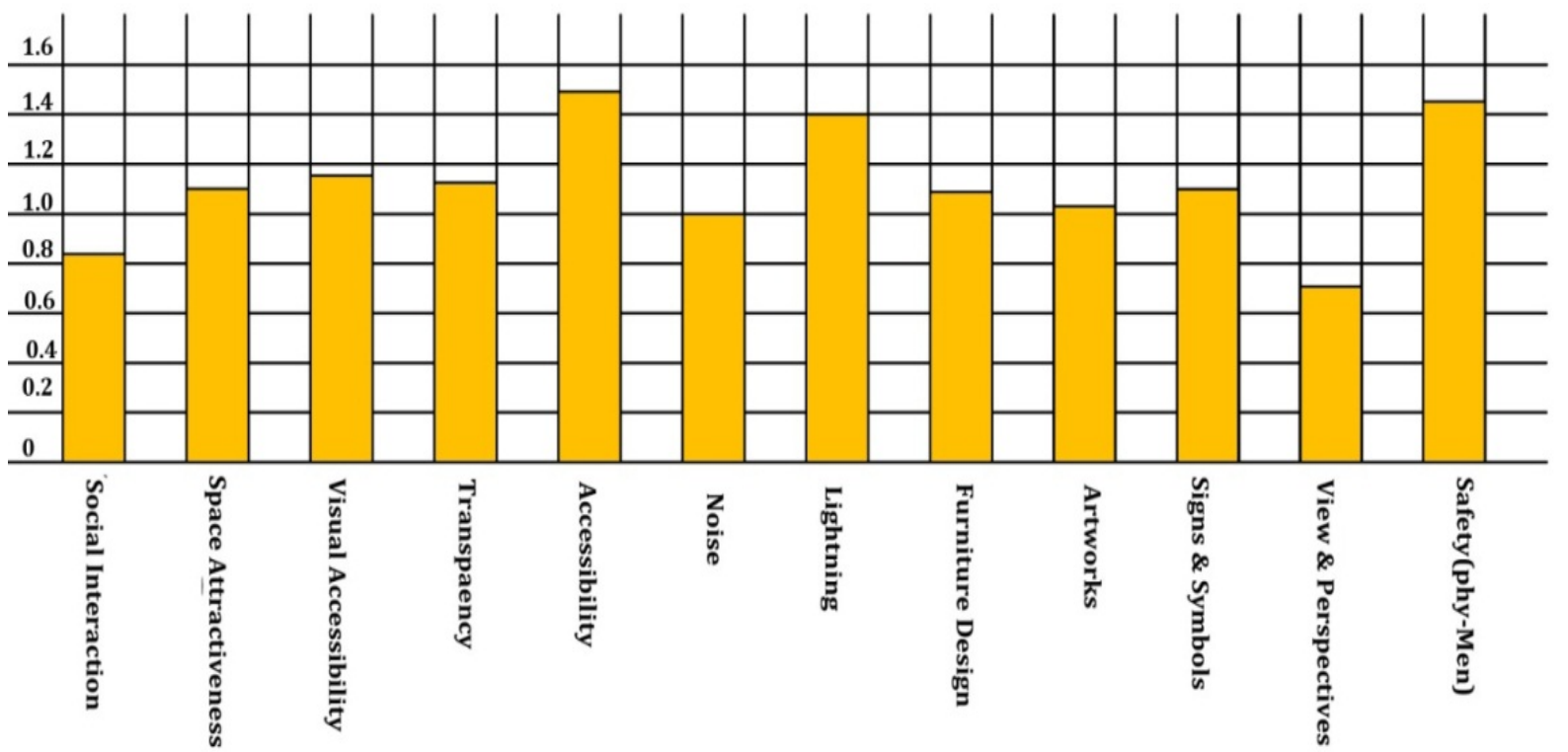

Fig. 6 Scaled architectural factors and human factors in subway stations-users' perspectives.

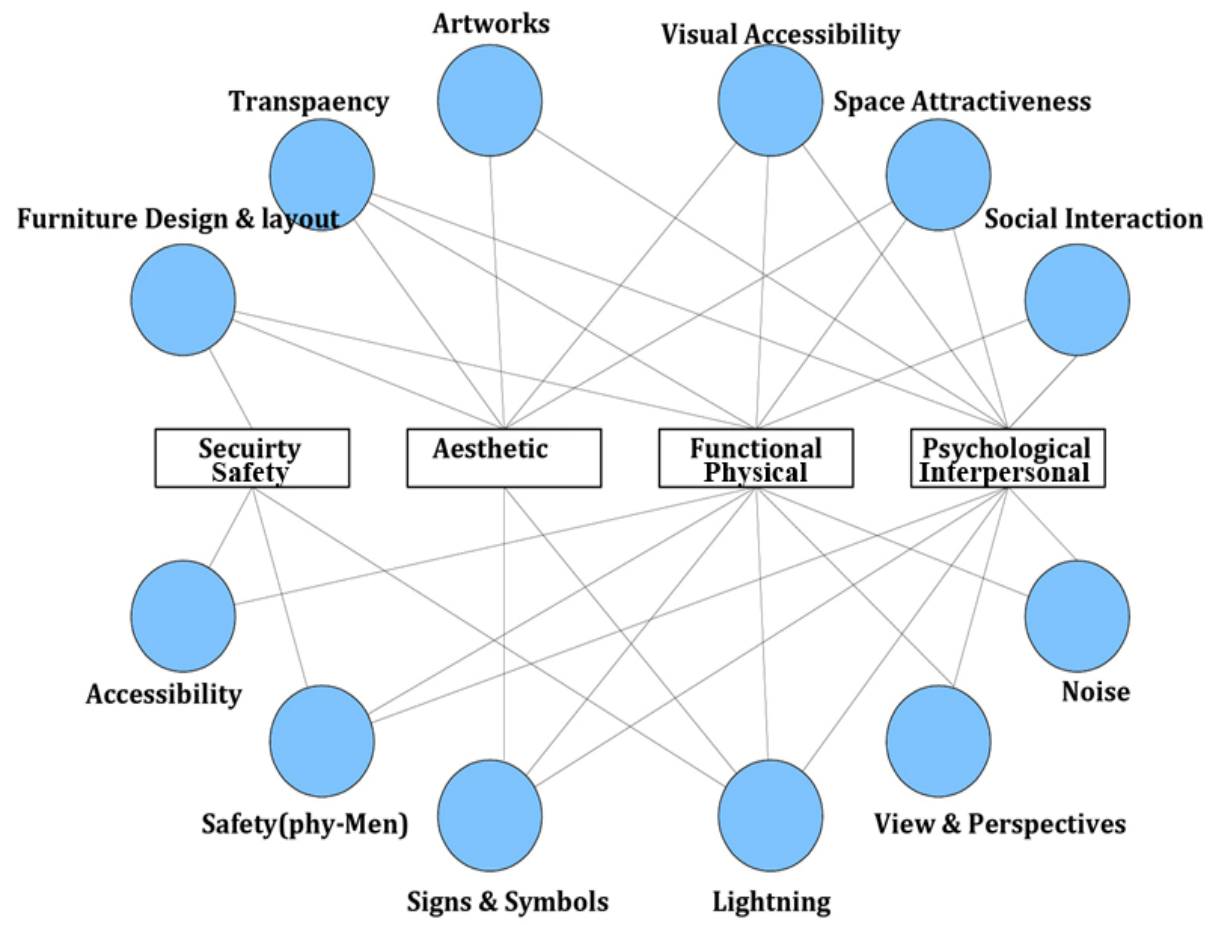

Fig. 7 Interrelationship between architectural factors which affect social interaction in subway stations. 


\section{Discussions}

This study informed the evidences which introduce the effects of architectural factors toward more humanistic and social spaces which not only improve the social interaction between users, but also are in better relationship with human beings. Subway station is one of the examples of public spaces as these types of buildings are in close relationship with the social life of people. Therefore, consideration of space qualities in such public buildings is important.

In Tehran subway stations, some of these qualities have been neglected. This study addressed important factors that can improve the users' satisfaction regarding the relationship between people and environment.

\section{Conclusions}

The findings of this study indicated that several architectural factors contribute with improving social interactions in Tehran subway stations: accessibility and safety/security are the most important architectural factors in this regard. Furthermore, lighting, visual accessibility, signs and symbols, transparency and space attractiveness are the other factors which affect the social interaction in Tehran subway station as well. Therefore, in order to improve the social interaction in subway stations and creating more humanistic spaces it is recommended to:

- avoiding long, slim corridors and facilitating better accessibility from the entrance to the trains;

- using non-slippery surfaces in order to prevent injuries and provide more safety for the people who are in a rush;

- security/safety considerations in the stations, especially around the platforms which are not equipped with screen doors;

- providing day lighting especially in underground stations;

- providing enough visual accessibility which promote the sense of place for the users and improve their mentally safety;

- placing appropriate signs and symbols in order to improve the spatial orientation in the station;

- providing seating appropriate furniture can improve the social interaction between people;

- locating pieces of artworks, nature mural, and transparency in spaces along with space attractiveness will be beneficial to provide a domestic and friendly space which facilitates the interactions among strangers.

Possible differences of architectural factors in different stations affect the perception and the judgment of the subjects which may limit the generalizability of the findings. Additionally, the amount of time for filling the questionnaire forms in the subway stations was limited which decreases the accuracy of the results. This study brought to light the architectural factors which contribute to more social spaces to fill out the gap of knowledge in subway station design, however, this study can just play a starting role in this area and further studies and investigations with the consideration of architectural factors, design intervention and human factors in specific stations are needed.

\section{References}

[1] B. Edwards, New Approaches to Railway Architecture, Taylor \& Francis, New York, 1996.

[2] Kittleson \& Associates, Transit Capacity and Quality of Service Manual, TCRP Web Document 6, Transit Cooperative Research Program, Transportation Research Board, 1999, http://nationalacademies.org/trb/publications/ tcrp/tcrp_webdoc_6-a.pdf (accessed Jan. 1, 2014).

[3] N. Salahshoor, Architectural Design of Subway Stations, Karvar Publication, Tehran, 2009.

[4] L. Pace, S. Fischer, A. Nichol, Transit Oriented Development and Rail Station Planning Guidelines, Adams County Department, 2007.

[5] M. Abaszadegan, R. Rezazadeh, M. Mohammadi, S. Alipoureshliki, Proposed model for users' satisfaction prediction, Hoviate Shahr Journal 6 (2010) 75-86.

[6] A. Nasreazadani, The Principles of Rail Stations Design, Sharif University Publication, Tehran, 2009.

[7] J. Lang, Creating Architectural Theory: The Role of the Behavioral Sciences in Environmental Design, Van 

Stations: An Evidence Based Design Approach

Nostrand Reinhold Company, New York, 1987.

[8] M. Carmona, T. Heath, O. Taner, S. Tiesdel, Public Places-Urban Spaces, Architecture Press, Oxford, 2004.

[9] S. Dusmisevic, S. Sariyildiz, A systematic quality assessment of underground space-public transport station, Cities 8 (1) (2001)13-23.

[10] S. Kandee, Intermodal concept in railway station design, Bangkok university knowledge center, Academic Review Journal 3 (2004) 1-9.

[11] Y. Tyrinopoulos, A. Comstamtinos, Public Transit User Satisfaction: Vriability and Policy Implications, Transport Policy, 2008, www.elsevier.com/locate/tranpol (accessed Jan. 1, 2014).

[12] M. Alavi, E. Ranjbar, An introduction of space quality design of entrances of subway station, Abadi Journal 1
(2009) 61-62.

[13] M.A. Khojasteghamari, Station design for disabled people, The Process of Architecture Design Journal 13 (2010) 56-67.

[14] B. Sampaio, O. Neto, Y. Sampaiom, Efficiency analysis of public transport systems: Lessons for insitutional Planning, Transportation Research Part A: Policy and Practice 42 (3) (2008) 445-454.

[15] R.V. Krejcie, D.W. Morgan, Kerjcie and Morgan determining sample size for research activities, Educational and Psychological Measurement 30 (1970) 607-610.

[16] The Location and Direction of Different Lanes of Subway Network in Tehran, http://metro.tehran.ir/ (accessed Jan. 1, 2014). 